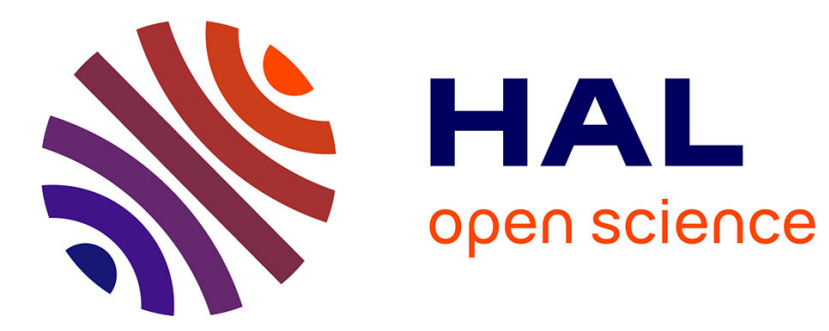

\title{
An improved algorithm for disaggregating microwave-derived soil moisture based on red, near-infrared and thermal-infrared data
}

Olivier Merlin, Al Bitar Ahmad, Jeffrey P. Walker, Yann H. Kerr

\section{- To cite this version:}

Olivier Merlin, Al Bitar Ahmad, Jeffrey P. Walker, Yann H. Kerr. An improved algorithm for disaggregating microwave-derived soil moisture based on red, near-infrared and thermal-infrared data. Remote Sensing of Environment, 2010, pp.RSE-07678. 10.1016/j.rse.2010.05.007 hal-00492461

\author{
HAL Id: hal-00492461 \\ https://hal.science/hal-00492461
}

Submitted on 23 Jun 2010

HAL is a multi-disciplinary open access archive for the deposit and dissemination of scientific research documents, whether they are published or not. The documents may come from teaching and research institutions in France or abroad, or from public or private research centers.
L'archive ouverte pluridisciplinaire HAL, est destinée au dépôt et à la diffusion de documents scientifiques de niveau recherche, publiés ou non, émanant des établissements d'enseignement et de recherche français ou étrangers, des laboratoires publics ou privés. 


\title{
An improved algorithm for disaggregating microwave-derived soil moisture based on red, near-infrared and thermal-infrared data
}

\author{
Olivier Merlin ${ }^{\mathrm{a}}$, Ahmad Al Bitar ${ }^{\mathrm{a}}$, Jeffrey P. Walker ${ }^{\mathrm{b}}$, Yann Kerr ${ }^{\mathrm{a}}$ \\ ${ }^{a}$ Centre d'Etudes Spatiales de la Biosphère (CESBIO), Toulouse, France \\ ${ }^{b}$ Civil and Environmental Engineering, The University of Melbourne, Australia
}

\section{Abstract}

Accurate high-resolution soil moisture data are needed for a range of agricultural and hydrologic activities. To improve the spatial resolution of $\sim 40 \mathrm{~km}$ resolution passive microwave-derived soil moisture, a methodology based on $1 \mathrm{~km}$ resolution MODIS (MODerate resolution Imaging Spectroradiometer) red, near-infrared and thermal-infrared data has been implemented at $4 \mathrm{~km}$ resolution. The three components of that method are (i) fractional vegetation cover, (ii) soil evaporative efficiency (defined as the ratio of actual to potential evaporation) and (iii) a downscaling relationship. In this paper, 36 different disaggregation algorithms are built from 3 fractional vegetation cover formulations, 3 soil evaporative efficiency models, and 4 downscaling relationships. All algorithms differ with regard to the representation of the nonlinear relationship between microwave-derived soil moisture and opticalderived soil evaporative efficiency. Airborne L-band data collected over an Australian agricultural area are used to both generate $\sim 40 \mathrm{~km}$ resolution microwave pixels and verify disaggregation results at $4 \mathrm{~km}$ resolution. Among the thirty-six disaggregation algorithms, one is identified as being more ro- 
bust (insensitive to soil, vegetation and atmospheric variables) than the others with a mean slope between MODIS-disaggregated and L-band derived soil moisture of 0.94 . The robustness of that algorithm is notably assessed by comparing the disaggregation results obtained using composited (averaged) Terra and Aqua MODIS data, and using data from Terra and Aqua separately. The error on disaggregated soil moisture is systematically reduced by compositing daily Terra and Aqua data with an error of 0.012 vol./vol..

Key words: disaggregation, downscaling, soil moisture, evaporation, nonlinear, SMOS, NAFE, MODIS.

\section{Introduction}

Many hydrological processes and interactions are nonlinear functions of land surface characteristics and state (e.g. McDonnell et al., 2007; Beven, 2008; Sivapalan, 2009). Their representation is thus dependent upon the observational scale for which it is developed and calibrated. For example, Nvkanen and Foufoula-Georgiou (2001) quantified the errors associated with nonlinearities in hydrological processes. They suggested that the mismatch of scales between calibration and application should be accounted for by modifying the nonlinear parameterizations. Otherwise, model-predicted water and energy fluxes were systematically biased. Another example was given by the recent study of Gebremichael et al. (2009) who demonstrated that the comparison of predicted streamflow to hydrographs did not allow the performance of a distributed physically-based model to be assessed, as the runoff production mechanism was not accurately reproduced at the application scale. They argued that the spatial distribution of soil moisture fields 
within the watershed provided more insight into actual physical processes.

Soil moisture remote sensing methods could help improve the representation of hydrological processes and their prediction at the watershed scale (e.g. Vereecken et al., 2008; Robinson et al., 2008). However, the resolution at which current and near-future remotely sensed soil moisture data are available is in general not compatible with the high spatial variability of landscape properties. In particular, the mean spatial resolution of the SMOS (Soil Moisture and Ocean Salinity, Kerr et al. (2001)) mission launched in November 2009 is $40 \mathrm{~km}$. Moreover, the spatial resolution of the forthcoming SMAP (Soil Moisture Active Passive, http://smap.jpl.nasa.gov) mission is also about $40 \mathrm{~km}$ for the passive sensor. Nevertheless, disaggregating remotely sensed soil moisture is one way to solve the mismatch of scales between spaceborne observations and model requirements, and SMAP proposes to provide a $10 \mathrm{~km}$ product by merging the radiometer with radar data. The challenge then lies in implementing such disaggregation approaches due to nonlinearity issues. Accounting for nonlinearities is critical because the subpixel variability of surface properties is generally high (this is actually the rationale for applying a disaggregation procedure).

Soil moisture relationships to temperature and vegetation parameters have been known since the early 90s with Carlson et al. (1994) being one of the first to formalize that relationship. Later, Chauhan et al. (2003) took a step towards disaggregating microwave-derived soil moisture to obtain highresolution soil moisture. Recently, Merlin et al. (2008b) improved that formalism by using a semi-empirical soil evaporative efficiency model to link microwave-derived soil moisture with red, near-infrared, and thermal-infrared 
data. In the methodology of Merlin et al. (2008b), nonlinearities are represented by three components. The first component is a formulation of the fractional vegetation cover derived from red and near-infrared data. Fractional vegetation cover is used to estimate soil evaporative efficiency (defined as the ratio of actual to potential soil evaporation) from remotely sensed surface temperature. The second component is a model of soil evaporative efficiency. It is used to estimate the slope between soil evaporative efficiency and soil moisture, subsequently used to translate spatial variations in soil evaporative efficiency into spatial variations in soil moisture. The third component is a downscaling relationship, which links soil moisture and soil evaporative efficiency observations across a range of scales. All three components control the representation of the relationship between microwave-derived soil moisture and optical-derived soil evaporative efficiency. This relationship is known to be strongly nonlinear (e.g. Noilhan and Planton, 1989; Komatsu, 2003). The impact of this nonlinear behaviour of soil evaporative efficiency on disaggregation results needs to be further investigated, as this was not fully addressed in Merlin et al. (2008b).

Another difficulty in using remote sensing methods is the nonlinear nature of the relationship between remote sensing observations and surface properties. For instance, the SMOS soil moisture retrieval algorithm (Kerr et al., 2006) accounts for nonlinearities between surface properties and the brightness temperatures observed at $40 \mathrm{~km}$ resolution by using information on soil type, land use and land cover at $4 \mathrm{~km}$ resolution in the forward model. Such an approach is expected to significantly reduce the impact of vegetation heterogeneity on SMOS soil moisture (Davenport et al., 2008; Loew, 2008). In 
the optical domain, nonlinearity issues are also present since the radiative transfer problem is linear in incident radiation but nonlinear in scattering (Mvneni et al., 1995).

In summary, one may state that hydrology, disaggregation and remote sensing face the same issue regarding nonlinear magnitudes: the combination of nonlinearity and spatial variability makes (hydrologic, disaggregation, radiative transfer) models strongly dependent upon the scale at which input and output data are considered. This issue is particularly important for disaggregation methodologies like in Merlin et al. (2008b) that apply to remote sensing data and are based on a hydrologic (the soil evaporative efficiency) model.

This study aims to develop a robust disaggregation algorithm, which better represents nonlinearities between microwave-derived soil moisture and the soil evaporative efficiency derived from red, near-infrared and thermalinfrared data. Consequently, the methodology of Merlin et al. (2008b) is tested using three different formulations of fractional vegetation cover, three different models of soil evaporative efficiency, and four different downscaling relationships. The data from the National Airborne Field Experiment 2006 (NAFE'06) are used to both generate $\sim 40 \mathrm{~km}$ resolution microwave pixels and verify disaggregation results at $4 \mathrm{~km}$ resolution.

\section{Data}

The NAFE'06 was conducted from 31 October to 20 November 2006 over a $40 \mathrm{~km}$ by $60 \mathrm{~km}$ area near Yanco $\left(-35^{\circ} \mathrm{N} ; 146^{\circ} \mathrm{E}\right)$ in southeastern Australia. While a full description of the data set is given in Merlin et al. (2008c), a 
brief overview of the most pertinent details are provided here. The data used in this study are comprised of L-band derived soil moisture and MODIS data collected over the Yanco area on twelve days.

\subsection{PLMR-derived soil moisture}

The near-surface soil moisture was retrieved from the $1 \mathrm{~km}$ resolution brightness temperature collected by the Polarimetric L-band Multibeam Radiometer (PLMR) on eleven days over the $40 \mathrm{~km}$ by $60 \mathrm{~km}$ study area: 31 October, 2, 3, 4, 5, 7, 9, 13, 14, 16, 18 November (Merlin et al., 2009b). The surface temperature data used for the PLMR soil moisture inversion came from MODIS data on clear sky days, and from in situ measurements on overcast days. The root mean square difference between PLMR-derived and ground-measured soil moisture at $1 \mathrm{~km}$ resolution was estimated as 0.03 vol./vol. in non-irrigated areas. A bias of about -0.09 vol./vol. was obtained over pixels including some irrigation. This bias was explained by a differ-

ence in sensing depth between the L-band radiometer $(\sim 0-3 \mathrm{~cm})$ and in situ measurements $(0-5.7 \mathrm{~cm})$, associated with a strong vertical gradient in the top $0-6 \mathrm{~cm}$ of the soil. Moreover, following the rainfall event on 3 November, the PLMR-derived soil moisture appeared affected by the presence of water intercepted by vegetation (Merlin et al., 2008c, b). In this study, data from this date were discarded.

\subsection{MODIS data}

The MODIS data used in this paper are the Version 5 MODIS/Terra (10:30 am) and MODIS/Aqua (1:30 pm) $1 \mathrm{~km}$ resolution daily surface temperature, and MODIS/Terra $250 \mathrm{~m}$ resolution 16-day red and near-infrared 
reflectances. The 16-day reflectance product was cloud free. In between the first (31 October) and last day (18 November) of $1 \mathrm{~km}$ resolution PLMR flights over the Yanco area, sixteen cloud free MODIS Version 5 surface temperature images were acquired including nine aboard Terra $(3,5,7,8,9,10$, 11, 17, 18 November) and seven aboard Aqua (31 October and 3, 4, 6, 8, 9, 17 November). In this study, the Terra and Aqua images on 3 November were discarded as for PLMR data. MODIS data were re-sampled on the same $1 \mathrm{~km}$ resolution grid as PLMR-derived soil moisture, and MODIS surface temperature was shifted of $(+1 \mathrm{~km} \mathrm{E} ;-0.5 \mathrm{~km} \mathrm{~N})$ and $(+2 \mathrm{~km} \mathrm{E}$; $0 \mathrm{~N}$ ) for Terra and Aqua respectively to maximize the spatial correlation with $1 \mathrm{~km}$ resolution MODIS NDVI, which was used as a reference for the co-registration.

\section{Methodology}

The disaggregation methodology of Merlin et al. (2008b) is first described, followed by different formulations of fractional vegetation cover, soil evaporative efficiency model, and downscaling relationships. The disaggregation resolution is set to four times the MODIS thermal resolution (4 km) as in Merlin et al. (2009a).

\subsection{A reference disaggregation algorithm}

The soil moisture $\theta_{4} \mathrm{~km}$ disaggregated at $4 \mathrm{~km}$ resolution can be expressed as:

$$
\begin{aligned}
\theta_{4 \mathrm{~km}}= & \theta_{40 \mathrm{~km}} \\
& +\left(\beta_{4 \mathrm{~km}}-\left\langle\beta_{4 \mathrm{~km}}\right\rangle_{40 \mathrm{~km}}\right) \times\left(\frac{\partial \theta}{\partial \beta}\right)_{40 \mathrm{~km}}
\end{aligned}
$$


with $\theta_{40 \mathrm{~km}}$ being the SMOS-scale soil moisture, $\beta_{4 \mathrm{~km}}$ the soil evaporative efficiency estimated at $4 \mathrm{~km}$ resolution, $\left\langle\beta_{4 \mathrm{~km}}\right\rangle_{40} \mathrm{~km}$ its average at $40 \mathrm{~km}$ resolution, and $\partial \theta / \partial \beta$ the partial derivative of soil moisture to soil evaporative efficiency. The $4 \mathrm{~km}$ resolution soil evaporative efficiency is estimated as:

$$
\beta_{4 \mathrm{~km}}=\frac{T_{\max }-T_{4 \mathrm{~km}}}{T_{\max }-T_{\min }}
$$

with $T_{4 \mathrm{~km}}$ the MODIS-derived soil temperature, $T_{\min }$ the minimum soil temperature and $T_{\max }$ the maximum soil temperature. MODIS-derived soil temperature $T_{4 \mathrm{~km}}$ is computed as:

$$
T_{4 \mathrm{~km}}=\frac{T_{\text {MODIS, } 4 \mathrm{~km}}-f_{4 \mathrm{~km}} T_{\mathrm{veg}}}{1-f_{4 \mathrm{~km}}}
$$

with $T_{\text {MODIS, }} 4 \mathrm{~km}$ being the MODIS surface temperature aggregated at $4 \mathrm{~km}$ resolution, $f_{4 \mathrm{~km}}$ the fractional vegetation cover and $T_{\mathrm{veg}}$ the vegetation temperature. Both minimum soil temperature in Equation (2) and vegetation temperature in Equation (3) are set to the minimum MODIS surface temperature observed within the study area. In Equation (2), the maximum soil temperature is set to the maximum value of the soil temperature derived at $1 \mathrm{~km}$ resolution by applying Equation (3) at $1 \mathrm{~km}$ resolution. Consequently, fractional vegetation cover is accounted for in $T_{4} \mathrm{~km}$ and $T_{\max }$, but not in $T_{\min }$. Fractional vegetation cover is estimated from the NDVI (Normalized Difference Vegetation Index) as in Gutman and Ignatov (1998):

$$
f_{\mathrm{G} 98}=\frac{\mathrm{NDVI}_{4 \mathrm{~km}}-\mathrm{NDVI}_{\mathrm{S}}}{\mathrm{NDVI}_{\mathrm{V}}-\mathrm{NDVI}_{\mathrm{S}}}
$$

with $\mathrm{NDVI}_{\mathrm{S}}$ and $\mathrm{NDVI}_{\mathrm{V}}$ being the NDVI for bare soil and fully-vegetated pixels, respectively. The NDVI is computed as:

$$
\mathrm{NDVI}_{4 \mathrm{~km}}=\frac{\mathrm{NIR}_{4 \mathrm{~km}}-\mathrm{R}_{4 \mathrm{~km}}}{\mathrm{NIR}_{4 \mathrm{~km}}+\mathrm{R}_{4 \mathrm{~km}}}
$$


with $\mathrm{NIR}_{4} \mathrm{~km}$ and $\mathrm{R}_{4} \mathrm{~km}$ being the MODIS near-infrared and red reflectances averaged at $4 \mathrm{~km}$ resolution. In Equation (1), the partial derivative is estimated using the formulation of Komatsu (2003):

$$
\beta_{\mathrm{mod}, \mathrm{K} 03}=1-\exp \left(-\theta / \theta_{\mathrm{C}, \mathrm{K} 03}\right)
$$

with $\theta_{\mathrm{C}, \mathrm{K} 03}$ being a semi-empirical parameter depending on soil type and boundary layer conditions (wind speed). Herein, the dependance of $\theta_{\mathrm{C}}$ on wind speed is neglected and $\theta_{\mathrm{C}}$ is referred to as a soil parameter.

Algorithm parameters are $\theta_{\mathrm{C}}$ and the reflectance over bare soil and fullcover vegetation in the red and near-infrared band. To determine reflectance end-members, two $250 \mathrm{~m}$ resolution pixels within the NAFE'06 area are identified as full-cover vegetation and bare soil. Note that $250 \mathrm{~m}$ reflectances are used intead of $1 \mathrm{~km}$ resolution NDVI in case the $1 \mathrm{~km}$ resolution pixel with the lowest NDVI is not free of vegetation (Montandon and Small, 2008). The red and near-infrared reflectance are determined as 0.20 and 0.25 for bare soil and 0.05 and 0.60 for full-cover vegetation, respectively. The calibration strategy of parameter $\theta_{\mathrm{C}}$ is presented in the Application section.

\subsection{Fractional vegetation cover}

Many formulations of fractional vegetation cover have been developed based on red and near-infrared reflectances. Recent reviews of methods are provided in Jiang et al. (2006); Kallel et al. (2007) and Jiménez-Muñoz et al. (2009). The large variety of formulations comes from the difficulty in deriving a vegetation index which is (i) highly sensitive to fractional vegetation cover, (ii) approximately linear over the full range of covers, and (iii) insensitive 
to view angle, atmospheric attenuation, and soil background. The objective here is not to test all existing formulations, but rather to compare the NDVI-based formulation from Gutman and Ignatov (1998) with two other simple formulations; one from Huete (1988) based on the SAVI (Soil Adjusted Vegetation Index) and another from Jiang et al. (2006) based on the SDVI (Scaled Difference Vegetation Index).

The reflectance observed over mixed pixels is a composite of both soil and vegetation contributions. To correct for soil effects, Huete (1988) developed a SAVI that was later optimized by Rondeaux et al. (1996). Fractional vegetation cover can be estimated as:

$$
f_{\mathrm{H} 88}=\frac{\mathrm{OSAVI}_{4 \mathrm{~km}}-\mathrm{OSAVI}_{\mathrm{S}}}{\mathrm{OSAVI}_{\mathrm{V}}-\mathrm{OSAVI}_{\mathrm{S}}}
$$

with $\mathrm{OSAVI}_{\mathrm{S}}$ and $\mathrm{OSAVI}_{\mathrm{V}}$ being the OSAVI (Optimized SAVI) over bare soil and fully-vegetated pixels, respectively. The OSAVI is computed as:

$$
\mathrm{OSAVI}_{4 \mathrm{~km}}=\frac{\mathrm{NIR}_{4 \mathrm{~km}}-\mathrm{R}_{4 \mathrm{~km}}}{\mathrm{NIR}_{4 \mathrm{~km}}+\mathrm{R}_{4 \mathrm{~km}}+X}
$$

with $X$ being an empirical parameter set to 0.16 (Rondeaux et al., 1996).

For heterogeneous surfaces, NDVI measurement does not aggregate linearly. Moreover, the relationship between NDVI and fractional vegetation cover is generally nonlinear (Baret et al., 1995; Carlson and Riplev, 1997). To overcome this limitation, Jiang et al. (2006) proposed a scale-invariant method to derive fractional vegetation cover from red and near-infrared reflectances. Accordingly, fractional vegetation cover can be estimated as:

$$
f_{\mathrm{J} 06}=\frac{\mathrm{DVI}_{4 \mathrm{~km}}-\mathrm{DVI}_{\mathrm{S}}}{\mathrm{DVI}_{\mathrm{V}}+\mathrm{DVI}_{\mathrm{S}}}
$$


with $\mathrm{DVI}_{\mathrm{S}}$ and $\mathrm{DVI}_{\mathrm{V}}$ being the DVI (Difference Vegetation Index) over bare soil and fully-vegetated pixels, respectively. The DVI is computed as:

$$
\mathrm{DVI}_{4} \mathrm{~km}=\mathrm{NIR}_{4 \mathrm{~km}}-\mathrm{R}_{4 \mathrm{~km}}
$$

Figure 1 compares the fractional vegetation cover derived at $1 \mathrm{~km}$ resolution from G98, H88 and J06 formulations. Significant differences are observed. In particular, the vegetation cover predicted by J06 is about half of that predicted by G98 or H88. Note that fractional vegetation cover was relatively low during NAFE'06 and this is the reason why all formulations seem to be linearly correlated. In fact, $f_{\mathrm{J} 06}$ is expected to increase rapidly in the higher range of vegetation cover, where the sensitivity of G98 formulation tends to decrease (Jiang et al., 2006).

\subsection{Soil evaporative efficiency}

A limitation of all the disaggregation methodologies of microwave-derived soil moisture based on optical data is the mismatch in sensing depth of microwave (several $\mathrm{cm})$ and thermal infrared $(\sim 1 \mathrm{~mm})$ radiometers. To quantify the errors due to this limitation, the soil evaporative efficiency model K03 (Komatsu, 2003) in Equation (6) is compared with two other formulations. Noilhan and Planton (1989) developed a simple expression (NP89) as a function of soil moisture:

$$
\beta_{\mathrm{mod}, \mathrm{NP} 89}=0.5-0.5 \cos \left(\pi \theta / \theta_{\mathrm{C}, \mathrm{NP} 89}\right)
$$

with $\theta_{\mathrm{C}, \text { NP89 }}$ being the soil moisture at field capacity. Another expression (LP92) of soil evaporative efficiency was derived by Lee and Pielke (1992):

$$
\beta_{\text {mod, LP92 }}=\left[0.5-0.5 \cos \left(\pi \theta / \theta_{\mathrm{C}, \mathrm{LP} 92}\right)\right]^{2}
$$


with $\theta_{\mathrm{C} \text {, LP92 }}$ being the soil moisture at field capacity. While K03 represents a soil layer of $\sim 1 \mathrm{~mm}, \mathrm{~N} 89$ and LP92 represent a soil layer of several $\mathrm{cm}$. Therefore K03 is consistent with the MODIS sensing depth and N89 and L92 are consistent with the SMOS sensing depth. As the disaggregation approach combines simulated SMOS and MODIS data using one of these models, this provides a unique opportunity to test the capability of each model to account for the mismatch in sensing depth of SMOS and MODIS radiometers.

Note that the same notation $\theta_{\mathrm{C}}$ is kept for all models because their physical meaning is equivalent: in Equations (6), (11) and (12) $\theta_{\mathrm{C}}$ controls in given atmospheric conditions the capability of the soil to evaporate the soil water. However, the scalar value of $\theta_{\mathrm{C}}$ for K03, NP89 and LP92 should be different, as each model is a different representation of soil evaporative efficiency.

Figure 2 plots the soil evaporative efficiency predicted by model K03, N89 and LP92 for a range of soil moisture values. Parameter $\theta_{\mathrm{C}}$ is set to $0.10,0.30$ and 0.30 vol./vol. for K03, NP89 and L92, respectively. The

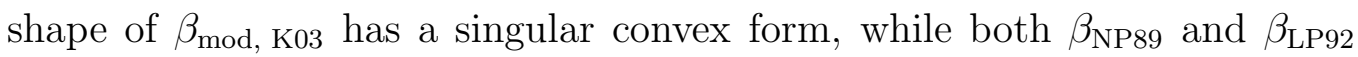
have an inflection point at around the middle of the soil moisture range. The concave form of soil evaporative efficiency at low soil moisture values has been observed in numerous experiments (e.g. Kondo et al., 1990; Lee and Pielke, 1992; Chanzv and Bruckler, 1993). In fact, N89 and L092 more accurately represent the behaviour of soil evaporative efficiency at low soil moisture values than K03 (Komatsu, 2003).

\subsection{Downscaling relationship}

Four different downscaling relationships are developed to assess the impact on disaggregation results of nonlinearities between soil evaporative effi- 
ciency, soil moisture and model parameter $\theta_{\mathrm{C}}$. Currently, two methodologies have been used to represent nonlinearities within a disaggregation framework: the Taylor series and the projection technique. The Taylor series has been successfully tested with a single variable $\theta$ in Merlin et al. (2008b, 2009a). In this paper, the Taylor approach is extended to two independent variables $\theta$ and $\theta_{\mathrm{C}}$. On the other hand, the projection technique (Merlin et al., 2005) is a powerful tool that reduces the dimensionality of the disaggregation problem. More specifically, it can be used to deterministically represent the nonlinear behaviour of multi-resolution observations. The projection approach was successfully applied to ground-based $-2.5 \mathrm{~cm}$ soil temperature in Merlin et al. (2006b), ground-based surface evaporative fraction in Merlin et al. (2008a), and Formosat-derived fractional green vegetation cover in Merlin et al. (2010). In this paper, it is applied to MODIS-derived soil evaporative efficiency.

\subsubsection{Genuine derivative approach}

The downscaling relationship D1 is a Taylor series of soil moisture $\theta$ at first order with respect to soil evaporative efficiency $\beta$ and model parameter $\theta_{\mathrm{C}}$ :

$$
\begin{aligned}
\theta_{4 \mathrm{~km}}^{(1)}= & \theta_{40 \mathrm{~km}} \\
& +\left(\beta_{4 \mathrm{~km}}-\left\langle\beta_{4 \mathrm{~km}}\right\rangle_{40 \mathrm{~km}}\right) \times\left(\frac{\partial \theta}{\partial \beta}\right)_{40 \mathrm{~km}} \\
& +\left(\theta_{\mathrm{C}, 4 \mathrm{~km}}-\left\langle\theta_{\mathrm{C}, 4 \mathrm{~km}}\right\rangle_{40 \mathrm{~km}}\right) \times\left(\frac{\partial \theta}{\partial \theta_{\mathrm{C}}}\right)_{40 \mathrm{~km}}
\end{aligned}
$$

with $\partial \theta / \partial \theta_{\mathrm{C}}$ being the partial derivative of soil moisture to model parameter $\theta_{\mathrm{C}}$. The partial derivatives are determined analytically using the model formulations K03, NP89 or LP92. 
Similarly, the downscaling relationship D2 is a Taylor series of soil moisture $\theta$ at second order with respect to soil evaporative efficiency $\beta$ and model parameter $\theta_{\mathrm{C}}$ :

$$
\begin{aligned}
\theta_{4 \mathrm{~km}}^{(2)}= & \theta_{40 \mathrm{~km}} \\
& +\left(\beta_{4 \mathrm{~km}}-\left\langle\beta_{4 \mathrm{~km}}\right\rangle_{40 \mathrm{~km}}\right) \times\left(\frac{\partial \theta}{\partial \beta}\right)_{40 \mathrm{~km}} \\
& +\frac{1}{2}\left(\beta_{4 \mathrm{~km}}-\left\langle\beta_{4 \mathrm{~km}}\right\rangle_{40 \mathrm{~km}}\right)^{2} \times\left(\frac{\partial^{2} \theta}{\partial \beta^{2}}\right)_{40 \mathrm{~km}} \\
+ & \left(\theta_{\mathrm{C}, 4 \mathrm{~km}}-\left\langle\theta_{\mathrm{C}, 4 \mathrm{~km}}\right\rangle_{40 \mathrm{~km}}\right) \times\left(\frac{\partial \theta}{\partial \theta_{\mathrm{C}}}\right)_{40 \mathrm{~km}} \\
+ & \frac{1}{2}\left(\theta_{\mathrm{C}, 4 \mathrm{~km}}-\left\langle\theta_{\mathrm{C}, 4 \mathrm{~km}}\right\rangle_{40 \mathrm{~km}}\right)^{2} \times\left(\frac{\partial^{2} \theta}{\partial \theta_{\mathrm{C}}^{2}}\right)_{40 \mathrm{~km}}
\end{aligned}
$$

with $\partial^{2} \theta / \partial \beta^{2}$ being the second partial derivative of soil moisture to soil evaporative efficiency $\beta$ and $\partial^{2} \theta / \partial \theta_{\mathrm{C}}^{2}$ the second partial derivative of soil moisture to model parameter $\theta_{\mathrm{C}}$.

Both D1 and D2 are called genuine derivative approaches because the finescale information that is used by both disaggregation algorithms is entirely controlled by model-predicted derivatives.

\subsubsection{Hybrid projective-derivative approach}

Alternatively to the genuine derivative downscaling relationships, other relationships can be developed by including the projection technique of Merlin et al. (2005). This approach consists of writing a Taylor series of soil moisture with respect to "projected soil evaporative efficiency".

At first order, the hybrid downscaling relationship noted D1' is:

$$
\begin{aligned}
\theta_{4 \mathrm{~km}}^{\left(1^{\prime}\right)}= & \theta_{40 \mathrm{~km}} \\
& +\left(\beta_{4 \mathrm{~km}}^{\text {proj }}-\left\langle\beta_{4 \mathrm{~km}}^{\text {proj }}\right\rangle_{40 \mathrm{~km}}\right) \times\left(\frac{\partial \theta}{\partial \beta}\right)_{40 \mathrm{~km}}
\end{aligned}
$$


with $\beta_{4 \mathrm{~km}}^{\text {proj }}$ being the soil evaporative efficiency projected using one of the models K03, NP89 or LP92. Projected soil evaporative efficiency is expressed as:

$$
\beta_{4 \mathrm{~km}}^{\mathrm{proj}}=\beta_{4 \mathrm{~km}}-\left[\beta_{\mathrm{mod}}\left(\theta_{4 \mathrm{~km}}, \theta_{\mathrm{C}, 4 \mathrm{~km}}\right)-\beta_{\bmod }\left(\theta_{4 \mathrm{~km}},\left\langle\theta_{\mathrm{C}, 4 \mathrm{~km}}\right\rangle_{40 \mathrm{~km}}\right)\right]
$$

with $\beta_{\text {mod }}\left(\theta_{4 \mathrm{~km}}, \theta_{\mathrm{C}, 4 \mathrm{~km}}\right)$ being the soil evaporative efficiency simulated using $4 \mathrm{~km}$ resolution soil moisture and $4 \mathrm{~km}$ resolution model parameter $\theta_{\mathrm{C}}$, and $\beta_{\text {mod }}\left(\theta_{4 \mathrm{~km}},\left\langle\theta_{\mathrm{C}, 4 \mathrm{~km}}\right\rangle_{40 \mathrm{~km}}\right)$ the soil evaporative efficiency simulated using 4 $\mathrm{km}$ resolution soil moisture and the model parameter aggregated at SMOS resolution $\left\langle\theta_{\mathrm{C}, 4 \mathrm{~km}}\right\rangle_{40 \mathrm{~km}}$. As $4 \mathrm{~km}$ resolution soil moisture is unknown before the disaggregation, it is initialized at the value observed at $40 \mathrm{~km}$ resolution and a loop on $\theta_{4 \mathrm{~km}}$ is run until convergence is achieved. In practice, two or three iterations are sufficient.

The hybrid projective-derivative approach can also be implemented at second order. The downscaling relationship denoted D2' is:

$$
\begin{aligned}
\theta_{4 \mathrm{~km}}^{\left(2^{\prime}\right)}= & \theta_{40 \mathrm{~km}} \\
& +\left(\beta_{4 \mathrm{~km}}^{\text {proj }}-\left\langle\beta_{4 \mathrm{~km}}^{\text {proj }}\right\rangle_{40 \mathrm{~km}}\right) \times\left(\frac{\partial \theta}{\partial \beta}\right)_{40 \mathrm{~km}} \\
& +\frac{1}{2}\left(\beta_{4 \mathrm{~km}}^{\text {proj }}-\left\langle\beta_{4 \mathrm{~km}}^{\text {proj }}\right\rangle_{40 \mathrm{~km}}\right)^{2} \times\left(\frac{\partial^{2} \theta}{\partial \beta^{2}}\right)_{40 \mathrm{~km}}
\end{aligned}
$$

The main difference between D1 and D1' and between D2 and D2' is the representation of the nonlinear behaviour of soil moisture with respect to model parameter $\theta_{\mathrm{C}}$. In the Taylor series approach, nonlinearities are represented by a second order derivative term whereas in the hybrid approach, they are represented by a difference between two modelled soil evaporative effiencies. It is hypothesized that the projection method will be more accurate, since no assumption is made on the relationship between soil moisture 
and model parameter. However, the robustness of the different approaches may also rely on the soil evaporative efficiency model used. These assumptions are tested with data in the following section.

\section{Application}

The three formulations of fractional vegetation cover (G98, H88 and J06), three models of soil evaporative efficiency (K03, NP89 and LP92) and four downscaling relationships (D1, D2, D1' and D2') are combined to generate 36 different disaggregation algorithms. Each of them is tested over the $40 \mathrm{~km}$ by $60 \mathrm{~km}$ Yanco area using the fourteen MODIS images. On 6, 8, 10, 11 and 17 November, the PLMR-derived soil moisture data of the day before are used. This extrapolation is valid because no rainfall occurred between the PLMR flight and MODIS overpass on each date. Random uncertainties in $4 \mathrm{~km}$ resolution PLMR-derived soil moisture can be estimated as the root mean square error in $1 \mathrm{~km}$ resolution PLMR-derived soil moisture (0.03 vol./vol., Merlin et al. (2009b) ) divided by the square root of the number (16) of $1 \mathrm{~km}$ pixels within $4 \mathrm{~km}$ resolution pixels: $0.03 / \sqrt{16}=0.008$ vol. $/$ vol..

\subsection{Estimating soil parameter $\theta_{C}$}

In the case study presented here, L-band data are available at the downscaling resolution $(4 \mathrm{~km})$. Therefore, models K03, NP89 and LP89 can be calibrated at $4 \mathrm{~km}$ resolution. In particular, the parameter $\theta_{\mathrm{C}}$ can be mapped at $4 \mathrm{~km}$ resolution using simultaneous observations of MODIS-derived soil evaporative efficiency and PLMR-derived soil moisture. This is achieved by inverting Equations (6), (11) and (12) and analytically expressing $\theta_{\mathrm{C}}$ as a function of $\beta$ and $\theta$. The calibration data set is comprised of the first seven 
MODIS images on 31 October (Aqua), 4 November (Aqua), 5 November (Terra), 6 November (Aqua), 7 November (Terra) and 8 November (Terra and Aqua). The remaining seven MODIS images are retained as validation data. Calibrated $\theta_{\mathrm{C}}$ values are obtained by averaging the soil parameter retrieved for each of the seven calibration images.

Note that MODIS-derived $\beta$ in Equation (2) depends on the formulation chosen for fractional vegetation cover. Consequently, $\theta_{\mathrm{C}, \mathrm{K} 03}, \theta_{\mathrm{C}, \mathrm{NP} 89}$ and $\theta_{\mathrm{C}, \mathrm{LP} 92}$ are also dependent on the $f$ formulation. To assess the impact of uncertainties in fractional vegetation cover on calibrated $\theta_{\mathrm{C}}$, Figure 3 plots for K03, N89 and L92 the soil parameter retrieved using H88 and J06 against that retrieved using G98 fractional vegetation fraction. One observes that the calibrated soil parameter value remains remarkably stable despite the relative high difference between fractional vegetation cover formulations (see Figure (1). Soil evaporative efficiency models seem to have low sensitivity to the formulation of fractional vegetation cover. This is due to the fact that both the numerator and denominator of the ratio in Equation (3) have the same sense of variation in fractional vegetation cover: an increase in the numerator is compensated by an increase in the denominator and vice versa. Nevertheless, Figure 3 indicates that the soil parameter retrieved using K03 is more stable than that retrieved using LP89 and LP92. The stability in $\theta_{\mathrm{C}}$ is quantified for each soil evaporative efficiency model K03, NP89 and LP92 by computing a stability index SI defined as:

$$
\mathrm{SI}=1-\frac{\left\|\theta_{\mathrm{C}, \mathrm{H} 88 / \mathrm{LP} 92}-\theta_{\mathrm{C}, \mathrm{G} 98}\right\|}{\left\|\theta_{\mathrm{C}, \mathrm{G} 98}-\left\langle\theta_{\mathrm{C}, \mathrm{G} 98}\right\rangle_{40} \mathrm{~km}\right\|}
$$

with $\left\|\theta_{\mathrm{C}, \text { H88/LP92 }}-\theta_{\mathrm{C}, \mathrm{G} 98}\right\|$ being the variability in $\theta_{\mathrm{C}}$ due to differences in the formulation of fractional vegetation cover and $\left\|\theta_{\mathrm{C}, \mathrm{G} 98}-\left\langle\theta_{\mathrm{C}, \mathrm{G} 98}\right\rangle_{40 \mathrm{~km}}\right\|$ 
the spatial variability of $\theta_{\mathrm{C}, \mathrm{G} 98}$. The higher SI, the more stable retrieved soil parameter. SI is estimated as 0.71, 0.66 and 0.49 for K03, NP89 and LP92, respectively. Therefore, K03 is shown to be more stable to uncertainties in fractional vegetation cover than NP89 and LP92.

Figure 4 presents the image at $4 \mathrm{~km}$ resolution of the $\theta_{\mathrm{C}, \mathrm{K} 03}, \theta_{\mathrm{C}, \mathrm{NP} 89}$ and $\theta_{\mathrm{C}, \mathrm{LP} 92}$ parameters retrieved using $f_{\mathrm{G} 98}$. One observes that retrieved parameter $\theta_{\mathrm{C}}$ and fractional vegetation cover $f_{\mathrm{G} 98}$ are largely independent. This confirms that retrieved $\theta_{\mathrm{C}}$ effectively characterizes the soil properties.

In the application to SMOS, L-band data will only be available at $\sim 40$ $\mathrm{km}$ resolution. Consequently, the approach presented here is limited to the calibration of $\theta_{\mathrm{C}}$ at $40 \mathrm{~km}$ resolution only. An important point is that the temporal dynamics of MODIS-derived soil evaporative efficiency could be used to retrieve $\theta_{\mathrm{C}}$ at higher resolution. However, the coupling of the disaggregation with an assimilation scheme as in Merlin et al. (2006a) will not be addressed in this paper. The objective here is to focus on the disaggregation scheme, and quantify the gain in accuracy and robustness when the soil parameter is provided at the downscaling resolution $(4 \mathrm{~km})$.

\subsection{Uniform soil parameter}

Disaggregation algorithms are first tested using a uniform value of $\theta_{\mathrm{C}}$ parameter within the $40 \mathrm{~km}$ resolution pixel. The SMOS-scale parameter $\theta_{\mathrm{C}, 40 \mathrm{~km}}$ is retrieved from the time series of $40 \mathrm{~km}$ resolution PLMR-derived soil moisture and $40 \mathrm{~km}$ resolution aggregated MODIS-derived soil evaporative efficiency between 31 October and 8 November. In this particular case, the partial derivative $\partial \theta / \partial \theta_{\mathrm{C}}$ in Equations (13) and (14) is null and the projected soil evaporative efficiency in Equations (15) and (17) is equal 
to soil evaporative efficiency. Consequently, D1 is identical to D1' and D2 is identical to D2'.

Downscaling relationships $\mathrm{D} 1=\mathrm{D} 1$ ' and $\mathrm{D} 2=\mathrm{D} 2$ ' are applied to the fourteen MODIS images of the NAFE'06 data set. Figure 5 presents the scatterplots of MODIS-disaggregated versus PLMR-derived soil moisture for each model K03, NP89 and LP92, and using the formulation of fractional vegetation cover given by J06. It is apparent that the scatter in disaggregated data is higher with K03 than with NP89 and LP92. However, the slope between disaggregated and PLMR-derived soil moisture is better with K03. When comparing the results obtained for $\mathrm{D} 1=\mathrm{D} 1$ ' and $\mathrm{D} 2=\mathrm{D} 2$ ', the addition of a second order term does not improve the disaggregation results. On the contrary, it increases the scatter.

Quantitative results in terms of root mean square difference, correlation coefficient and slope between MODIS-disaggregated and PLMR-derived soil moisture are presented in Table 1. Statistical results are presented for each soil evaporative efficiency model and each fractional vegetation cover formulation. They indicate that the formulation of fractional vegetation cover has a small impact on the disaggregation. In fact, vegetation cover was relatively low during NAFE'06 so that the difference between formulations at high covers is not so visible with these data. Nevertheless, the formulation from J06 decreases the error, slightly but systematically, and increases the correlation coefficient and slope. Regarding the soil evaporative efficiency model, great differences are apparent between K03 and NP89 or LP92. Although the error is about 0.03 vol./vol. for K03 and 0.02 vol./vol. for NP89 and LP92, the slope is about 1 for K03 and 0.6-0.7 for NP89 and LP92. Consequently, the 
disaggregation algorithms based on K03 are less accurate but more robust than those based on NP89 or LP92. When comparing D1=D1' and D2=D2' in Table 1, statistical results are slightly degraded by adding a second order term into the downscaling relationship.

\subsection{Space-varying soil parameter}

Soil parameter $\theta_{\mathrm{C}}$ is now used at $4 \mathrm{~km}$ resolution in the disaggregation algorithms. The comparison between D1 and D1' and between D2 with D2' aims at assessing the stability of the hybrid derivative-projective versus the genuine derivative approach.

\subsubsection{First-order approximation}

Disaggregation results from D1 and D1' are presented in Figure 6 and in Table 1. It is apparent that the scatter in disaggregated soil moisture is much reduced by accounting for variability of the soil parameter. In particular, for the algorithm combining D1 and K03 the error is decreased from 0.030 vol./vol. in the case "uniform $\theta_{\mathrm{C}}$ " to 0.020 vol./vol. in the case "varying $\theta_{\mathrm{C}}$ ". When comparing D1 and D1' in Table 1 it is apparent that the correlation coefficient is generally higher for D1' and the slope generally higher for D1, regardless of the model K03, NP89 or LP92. These contrasting results do not allow selection of a preferred downscaling relationship, since each has its own advantage and drawback. However, NP89 makes the disaggregation more accurate than with K03 and LP92, but less robust than with K03 since the slope is systematically closer to 1 with K03. 


\subsubsection{Adding second-order term}

Disaggregation results from D2 and D2' are presented in Figure 7 and in Table 1. It is apparent that the addition of a second-order term in the downscaling relationship generally degrades disaggregation results. One exception however is the case of D2' with K03. For D2' based on model K03, the second order term significantly improves (as compared with D1') the slope between MODIS-disaggregated and PLMR-derived soil moisture. When comparing D2 and D2' in Table 11 the hybrid projective-derivative approach D2' is practically equivalent to the genuine derivative approach D2, except for K03. For K03, the projection increases the correlation coefficient from 0.86 to 0.89 and decreases the slope from 0.97 to 0.94 .

\subsubsection{Summary}

The analysis of statistical results from the thirty six disaggregation algorithms indicate that:

- for all algorithms, knowledge of soil parameter $\theta_{\mathrm{C}}$ at the downscaling resolution has a strong impact on disaggregation results.

- although the formulation of fractional vegetation cover has a small impact for the conditions that prevailed during NAFE'06 (low vegetation cover at $4 \mathrm{~km}$ resolution), results are generally superior with J06 formulation.

- all algorithms are more accurate with the NP89 model but more robust with K03.

- the combination of D2' (second-order hybrid derivative-projective ap- 
proach) and K03 model is a good compromise between accuracy and robustness.

\subsection{Combining the MODIS data aboard Terra and Aqua}

Downscaling relationships are now applied to MODIS data on 9 November when both Terra and Aqua images are available and cloud free. The idea is to combine Terra and Aqua data within the disaggregation scheme, and assess whether output data are improved as compared with considering Terra and Aqua data separately. In practice, the soil moisture disaggregated using the MODIS data collected aboard Terra is averaged with the soil moisture disaggregated using the MODIS data collected aboard Aqua platform on the same day. As Terra and Aqua data are independent observations, combining data is expected to reduce random uncertainties in disaggregation results. Moreover, the reduction in uncertainty is foreseen to be all the more important as the downscaling relationship is robust. This test is implemented here to assess the robustness of the disaggregation algorithm composed of downscaling relationship D2', soil evaporative efficiency model K03, and fractional vegetation cover J06.

Figure 8 plots MODIS-disaggregated versus PLMR-derived soil moisture for 9 November Terra and Aqua composited data, and for each of the six cases D1=D1' (first-order and uniform parameter), D2=D2' (second-order and uniform parameter), D1 (first-order genuine derivative and space-varying parameter), D2 (second-order genuine derivative and space-varying parameter), D1' (first-order projective-derivative and space-varying parameter) and D2' (second-order projective-derivative and space-varying parameter). Consistent with previous results, it is observed that D2' is the most efficient down- 
scaling relationship. As compared with the genuine derivative approach D2, the hybrid derivative-projective approach D2' reduces random uncertainties in disaggregated soil moisture. Moreover, D2' improves the slope between MODIS-disaggregated and PLMR-derived soil moisture as compared with the first-order projective-derivative D1'.

Table 2 compares the results obtained from Terra and Aqua composited (averaged) data with the average of the results obtained from Terra and Aqua data separately. An important point is that the root mean square difference, correlation coefficient and slope between MODIS-disaggregated and PLMR-derived soil moisture are systematically improved by combing Terra and Aqua data, regardless of the downscaling relationship. This means that the temporal aggregation of MODIS data is an efficient way to reduce random uncertainties in disaggregated soil moisture. Table 2 also indicates that D2' is the most accurate with an error of 0.012 vol./vol. and a correlation coefficient of 0.90. Note that the slope between MODIS-disaggregation and PLMR-derived soil moisture is only 0.77 for D2', whereas it is 0.86 for D2. In fact, the relatively low slope for D2' on 9 November is due to the uncertainty associated with a poor representation of $\beta$ by K03 at low soil moisture values. For D2, this effect seems to be compensated by a higher scatter in disaggregated soil moisture. Nevertheless, when looking at the disaggregated values above 0.05 vol./vol. in Figure 8; , the slope between MODIS-disaggregated and PLMR-derived soil moisture is very close to 1.

As an illustration of final results, Figure 9 presents a spatial plot over the NAFE'06 area of (i) the soil moisture disaggregated by D1=D1' (ii) the soil moisture disaggregated by D2' and (iii) PLMR-derived soil moisture. The 
spatial variability of $4 \mathrm{~km}$ resolution surface soil moisture is better represented using algorithm D2'.

\subsection{Assumptions and operational applicability}

The disaggregation approach has been evaluated using the NAFE'06 data set. To thoroughly assess its robustness in a wider range of soil moisture, vegetation and evaporative demand conditions, the methodology should be tested over other regions. Its operational applicability over large areas is conditioned by five main assumptions, which are discussed below.

1. Cloud-free conditions: MODIS data are available for clear-sky conditions only.

2. Mismatch of overpass times: the MODIS/Terra overpass time at 10 am (ascending), MODIS/Aqua overpass time at $1 \mathrm{pm}$ (ascending), and the SMOS overpass time at 6 am (descending) are all different. In the methodology, it is assumed that the soil moisture pattern is spatially persistent for a few hours after the SMOS overpass. If no rainfall occurs in between, this assumption is generally met because the decay timescale of $0-5 \mathrm{~cm}$ soil moisture (several days) is much longer than the time difference (several hours) between MODIS and SMOS acquisition times.

3. Mismatch of sensing depths: the SMOS L-band sensing depth is about $5 \mathrm{~cm}$ while the MODIS thermal infrared only gives an estimate of the skin temperature. Moreover, soil evaporative efficiency is better described using observations in the first $5 \mathrm{~cm}$ of the soil (e.g. Chanzy and Bruckler, 1993). In the methodology, it is assumed that 
the soil skin temperature derived from MODIS data has a horizontal spatial correlation with the $0-5 \mathrm{~cm}$ soil temperature. This assumption is required to estimate soil evaprative efficiency from $1 \mathrm{~mm}$ MODIS thermal infrared data (Nishida et al., 2003). As soil skin temperature is also correlated with air temperature, one implicitly assumes that air temperature is relatively uniform within the SMOS pixel. This was actually verified with the NAFE'06 data set because the $\theta_{\mathrm{C}}$ parameter was found to be temporally persistent, and thus relatively independent from atmospheric conditions.

4. MODIS-derived soil evaporative efficiency: estimation of soil evaporative efficiency using the "triangle method" relies on reflectance and temperature end-members. The accuracy in determining end-members from the MODIS images may vary with surface conditions. In this paper, it is assumed that extreme conditions (dry, wet, full-cover, bare soil) can be observed at the resolution of the MODIS spectral bands. Note that end-members could also be estimated using look-up tables (especially for vegetation and soil reflectances) or using ground-based ancillary data (the minimum soil temperature can be set to air temperature or to the surface temperature of a water body). Limitations of the triangle approach and prospects for determining end-members can be found in Carlson (2007).

5. Availability of the $\theta_{\mathrm{C}}$ parameter. This parameter may be difficult to obtain from ancillary data as it is expected to depend on soil texture, soil structure (pore-size distribution and connectivity), soil aggregates and the presence of biomass. Consequently, a more robust approach is 
to estimate $\theta_{\mathrm{C}}$ at $40 \mathrm{~km}$ resolution from SMOS and aggregated MODIS data. As the optimal application of the methodology requires $\theta_{\mathrm{C}}$ at the downscaling resolution, future research should tackle the issue of estimating $\theta_{\mathrm{C}}$ at $4 \mathrm{~km}$ resolution using a time series of SMOS and MODIS data.

\section{Conclusions}

Thirty six different disaggregation algorithms are compared using the NAFE'06 data set. Results indicate that (i) the soil parameter of the soil evaporative efficiency model has a strong impact on disaggregated soil moisture, (ii) the formulation of fractional vegetation cover has a small impact with the NAFE'06 data set, (iii) disaggregation algorithms are (slightly) more accurate with a cosine-based soil evaporative efficiency model, but more robust with an exponential-based model and (iv) the second-order hybrid derivative-projective approach combined with the exponential-based model seems to be a good compromise between accuracy and robustness. The robustness of that algorithm is assessed by compositing (averaging) the soil moisture disaggregated using the MODIS data collected aboard Terra and Aqua. The error on disaggregated soil moisture is systematically reduced by compositing daily Terra and Aqua data, and the most robust algorithm is found to be the most accurate with an error of 0.012 vol./vol..

In the application to SMOS, L-band data will only be available at $\sim 40$ $\mathrm{km}$ resolution. Consequently, the current approach will not allow calibrating the $\theta_{\mathrm{C}}$ parameter at the downscaling resolution, but at the $40 \mathrm{~km}$ resolution only. To estimate $\theta_{\mathrm{C}}$ at the downscaling resolution, future research 
should tackle the issue of combining the spatial and temporal information of data. In particular, the dynamics of disaggregated soil moisture fields is foreseen to provide some information on the spatial distribution of $\theta_{\mathrm{C}}$. A disaggregation-assimilation coupling scheme may allow improving disaggregation results iteratively.

\section{Acknowledgements}

The NAFE'06 participants are gratefully acknowledged for their participation in collecting this extensive data set. The National Airborne Field Experiments have been made possible through infrastructure (LE0453434 and LE0560930) and research (DP0557543) funding from the Australian Research Council, and the collaboration of a large number of scientists from throughout Australia, United States and Europe. Initial setup and maintenance of the study catchments was funded by a research grant (DP0343778) from the Australian Research Council and by the CRC for Catchment Hydrology. This work was funded by the French program Terre-Océan-Surfaces-ContinentalesAtmosphère and the Centre National de la Recherche Scientifique. 


\section{References}

Baret, F., Clevers, J. G. P. W., Steven, M. D., 1995. The robustness of canopy gap fraction estimates from red and near-infrared reflectances: a comparison of approaches. Remote Sens. Environ. 54, 141-151.

Beven, K., 2008. On doing better hydrological sciences. Hydrol. Proc. 22, 3549-3553, doi:10.1002/hyp.7108.

Carlson, T., 2007. An overview of the 'triangle method' for estimating surface evapotranspiration and soil moisture from satellite imagery. Sensors 7, 1612-1629.

Carlson, T. N., Gillies, R. R., Perry, E. M., 1994. A method to make use of thermal infrared temperature and ndvi measurements to infer soil water content and fractional vegetation cover. Remote Sens. Rev. 52, 45-59.

Carlson, T. N., Ripley, D. A., 1997. On the relation between NDVI, fractional vegetation cover, and leaf area index. Remote Sens. Environ. 62, 241-252.

Chanzy, A., Bruckler, L., 1993. Significance of soil surface moisture with respect to daily bare soil evaporation. Water Resour. Res. 29 (4), 11131125 .

Chauhan, N. S., Miller, S., Ardanuy, P., 2003. Spaceborne soil moisture estimation at high resolution: a microwave-optical/IR synergistic approach. Int. J. Remote Sens. 24 (22), 4599-4622.

Davenport, I. J., Sandells, M. J., Gurney, R. J., 2008. The effects of scene 
heterogeneity on soil moisture retrieval from passive microwave data. Adv. Water Res. 31, 1494-1502, doi:10.1016/j.advwatres.2008.06.002.

Gebremichael, M., Rigon, R., Bertoldi, G., Over, T. M., 2009. On the scaling characteristics of observed and simulated spatial soil moisture fields. Nonlin. Processes Geophys. 16, 141-150.

Gutman, G., Ignatov, A., 1998. The derivation of the green vegetation fraction from NOAA/AVHRR data for use in numerical weather prediction models. Int. J. Remote Sens. 19, 1533-1543.

Huete, A. R., 1988. A soil-adjusted vegetation index (SAVI). Remote Sens. Environ. 25, 295-309.

Jiang, Z., Huete, A. R., Chen, J., Chen, Y., Li, J., Yan, G., Zhang, X., 2006. Analysis of NDVI and scaled difference vegetation index retrievals of vegetation fraction. Remote Sens. Environ. 101, 366-378.

Jiménez-Muñoz, J. C., Sobrino, J. A., Plaza, A., Guanter, L., Moreno, J., Martínez, P., 2009. Comparison between fractional vegetation cover retrievals from vegetation indices and spectral mixture analysis: case study of PROBA/CHRIS data over an agricultural area. Sensors 9, 768-793, doi:10.3390/s90200768.

Kallel, A., Le Hégarat-Mascle, S., Ottlé, C., Hubert-Moy, L., 2007. Determination of vegetation cover fraction by inversion of a four-parameter model based on isoline parameterization. Remote Sens. Environ. 111, 553-566, doi:10.1016/j.rse.2007.04.006. 
Kerr, Y. H., Waldteufel, P., Richaume, P., Davenport, I., Ferrazzoli, P., Wigneron, J.-P., 2006. SMOS level 2 processor soil moisture Algorithm Theoretical Basis Document (ATBD). SM-ESL (CBSA). Vol. SO-TN-ESLSM-GS-0001, V5.a. CESBIO, Toulouse.

Kerr, Y. H., Waldteufel, P., Wigneron, J.-P., Martinuzzi, J.-M., Font, J., Berger, M., 2001. Soil moisture retrieval from space: the soil moisture and ocean salinity (SMOS) mission. IEEE Trans. Geosci. Remote Sens. 39, 1729-1735.

Komatsu, T. S., 2003. Towards a robust phenomenological expression of evaporation efficiency for unsaturated soil surfaces. J. Appl. Meteor. 42, 13301334.

Kondo, J., Saigusa, N., Sato, T., 1990. A parameterization of evaporation from bare soil surface. J. Appl. Meteor. 29, 385-389.

Lee, T. J., Pielke, R. A., 1992. Estimating the soil surface specific humidity. J. Appl. Meteor. 31, 480-484.

Loew, A., 2008. Impact of surface heterogeneity on surface soil moisture retrievals from passive microwave data at the regional scale: The Upper Danube case. Remote Sens. Environ. 112, 231-248.

McDonnell, J. J., Sivapalan, M., Vaché, K., Dunn, S., Grant, G., Haggerty, R., Hinz, C., Hooper, R., Kirchner, J., Roderick, M. L., Selker, J., Weiler, M., 2007. Moving beyond heterogeneity and process complexity: a new vision for watershed hydrology. Water Resour. Res. 43 (W07301), doi:10.1029/2006WR005467. 
Merlin, O., Al Bitar, A., Walker, J., Kerr, Y., 2009a. A sequential model for disaggregating surface soil moisture observations using multiresolution thermal sensors. Remote Sens. Environ. 113 (10), 2275-2284, doi:10.1016/j.rse.2009.06.012.

Merlin, O., Chehbouni, G., Boulet, G., Kerr, Y., 2006a. Assimilation of disaggregated microwave soil moisture into a hydrologic model using coarse-scale meterological data. J. Hydrometeor. 7, 1308-1322.

Merlin, O., Chehbouni, G., Kerr, Y., Goodrich, D., 2006b. A downscaling method for distributing surface soil moisture within a microwave pixel: Application to the Monsoon'90 data. Remote Sens. Environ. 101, 379-389.

Merlin, O., Chehbouni, G., Kerr, Y., Njoku, E. G., Entekhabi, D., 2005. A combined modeling and multi-spectral/multi-resolution remote sensing approach for disaggregation of surface soil moisture: Application to SMOS configuration. IEEE Trans. Geosci. Remote Sens. 43 (9), 2036-2050.

Merlin, O., Chehbouni, G., Walker, J. P., Panciera, R., Kerr, Y., 2008a. A simple method to disaggregate passive microwave based soil moisture. IEEE Trans. Geosc. Remote Sens. 46 (3), doi:10.1109/TGRS.2007.914807.

Merlin, O., Duchemin, B., Hagolle, O., Jacob, F., Coudert, B., Chehbouni, G., Dedieu, G., Garatuza, J., Kerr, Y., 2010. Disaggregation of MODIS surface temperature over an agricultural area using a time series of Formosat-2 images. Remote Sens. Environ.Doi:10.1016/j.rse.2010.05.025.

Merlin, O., Walker, J. P., Chehbouni, A., Kerr, Y., 2008b. Towards deterministic downscaling of SMOS soil moisture using MODIS de- 
rived soil evaporative efficiency. Remote Sens. Environ. 112, 3935-3946, doi:10.1016/j.rse.2008.06.012.

Merlin, O., Walker, J. P., Kalma, J. D., Kim, E. J., Hacker, J., Panciera, R., Young, R., Summerell, G., Hornbuckle, J., Hafeez, M., Jackson, T. J., 2008c. The NAFE'06 data set: towards soil moisture retrieval at intermediate resolution. Adv. Water Resour. 31, 1444-1455, doi:10.1016/j.advwatres.2008.01.018.

Merlin, O., Walker, J. P., Panciera, R., Escorihuela, M. J., Jackson, T. J., 2009b. Assessing the SMOS soil moisture retrieval parameters with highresolution NAFE'06 data. Geosci. Remote Sens. Lett. 6 (4), 635-639, doi:10.1109/LGRS.2009.2012727.

Montandon, L. M., Small, E. E., 2008. The impact of soil reflectance on the quantification of the green vegetation fraction from NDVI. Remote Sens. Environ. 112, 1835-1845, doi:10.1016/j.rse.2007.09.007.

Myneni, R. B., Maggion, S., Iaquinta, J., Privette, J. L., Gobron, N., Pinty, B., Kimes, D. S., Verstraete, M. M., Williams, D. L., 1995. Optical remote sensing of vegetation: modeling, caveats and algorithms. Remote Sens. Environ. 51, 169-188.

Nishida, K., Nemani, R. R., Glassy, J. M., Running, S. W., 2003. Development of an evapotranspiration index from Aqua/MODIS for monitoring surface moisture status. IEEE Trans. Geosci. Remote Sens. 41 (2), 493501. 
Noilhan, J., Planton, S., 1989. A simple parameterization of land surface processes for meteorological models. Mon. Wea. Rev. 117, 536-549.

Nykanen, D. K., Foufoula-Georgiou, E., 2001. Soil moisture variability and scale-dependency of nonlinear parameterizations in coupled landatmosphere models. Adv. Water Res. 24, 1143-1157.

Robinson, D. A., Campbell, C. S., Hopmans, J. W., Hornbuckle, B. K., Jones, S. B., Knight, R., Ogden, F., Selker, J., Wendroth, O., 2008. Soil moisture measurements for ecological and hydrological watershed scale observatories: a review. Vadose Zone 7, 358-389, doi:10.2136/vzj2007.0143.

Rondeaux, G., Steven, M., Baret, F., 1996. Optimization of soil-adjusted vegetation indices. Remote Sens. Environ. 55, 95-107.

Sivapalan, M., 2009. The secret to 'Doing better hydrological science': change the question! Hydrol. Proc. 23, 1391-1396, doi:10.1002/hyp.7242.

Vereecken, H., Huisman, J. A., Bogena, H., Vanderborght, J., Vrugt, J. A., Hopmans, J. W., 2008. On the value of soil moisture measurements in vadose zone hydrology: a review. Water Resour. Res. 44 (W00D06), doi:10.1029/2008WR006829. 
Table 1: Root mean square difference (RMSD), correlation coefficient (R) and slope between MODIS-disaggregated and PLMR-derived soil moisture. Superior statistical results are highlighted in bold.

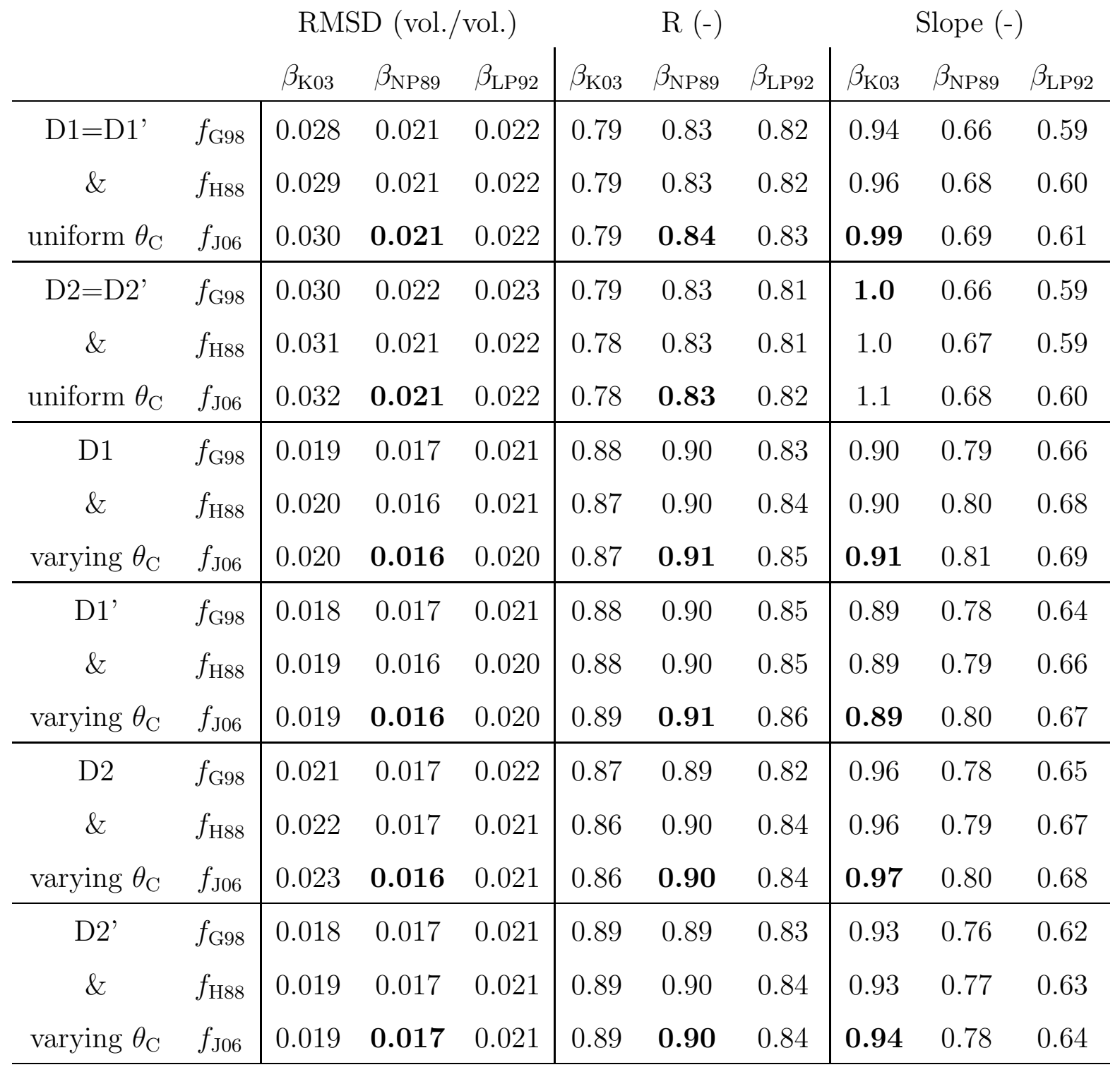


Table 2: Root mean square difference (RMSD), correlation coefficient (R) and slope between MODIS-disaggregated and PLMR-derived soil moisture. The results are for K03 and J06 combination and are evaluated for 9 November Terra and Aqua composited data (and as the average of the statistical results obtained for Terra and Aqua data separately).

\begin{tabular}{cccc} 
& RMSD (vol./vol.) & $\mathrm{R}(-)$ & Slope $(-)$ \\
\hline D1 = D1' & $0.022(0.024)$ & $0.77(0.74)$ & $0.94(0.87)$ \\
D2 = D2' & $0.023(0.025)$ & $0.78(0.76)$ & $1.0(0.96)$ \\
D1 & $0.015(0.018)$ & $0.84(0.78)$ & $0.75(0.72)$ \\
D2 & $0.016(0.019)$ & $0.84(0.80)$ & $0.86(0.80)$ \\
D1' & $0.013(0.017)$ & $0.88(0.80)$ & $0.71(0.67)$ \\
D2 & $0.012(0.016)$ & $0.90(0.83)$ & $0.77(0.72)$ \\
\hline
\end{tabular}




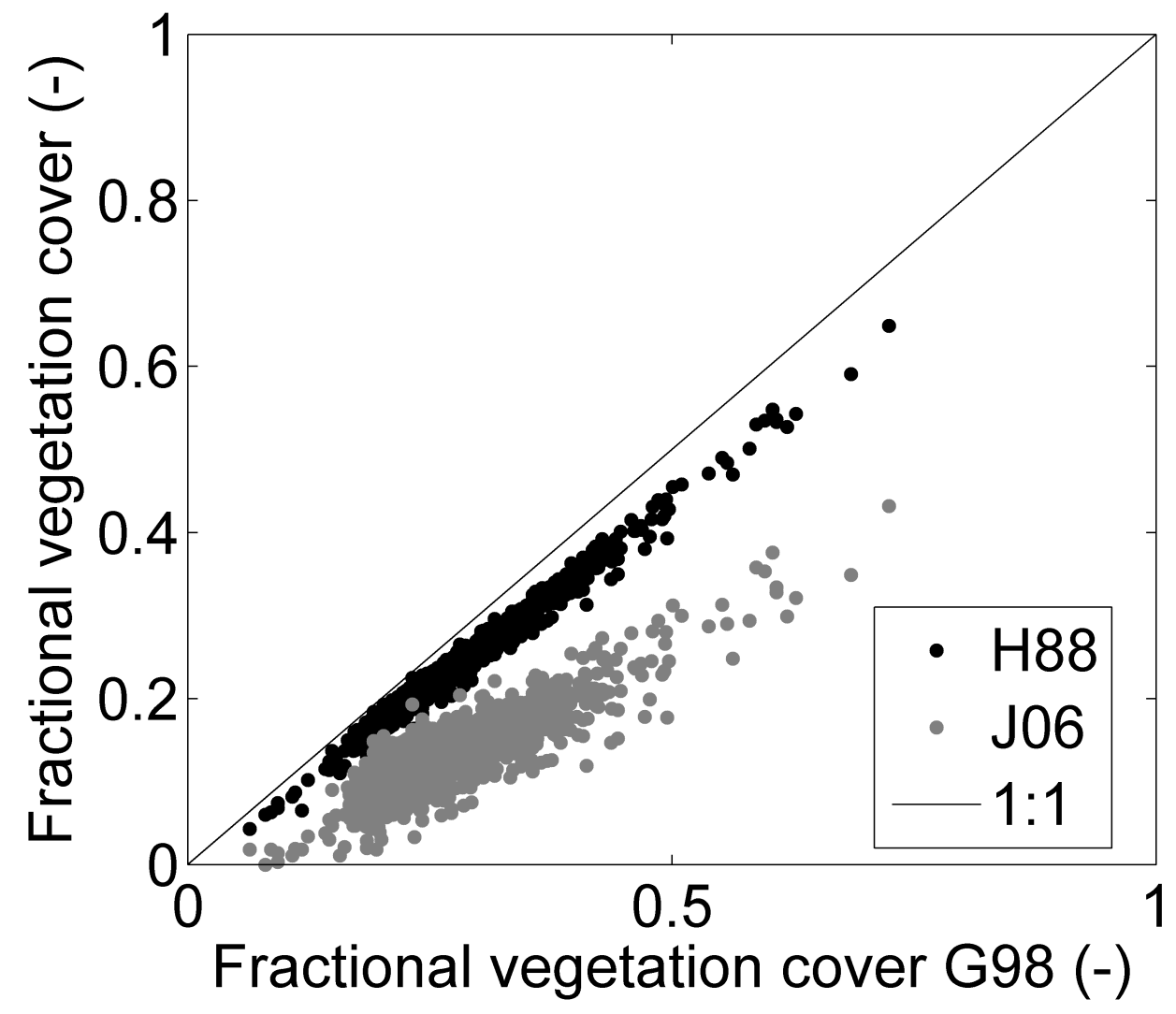

Figure 1: Scatterplot of the fractional vegetation cover $f$ derived from the formulation of Huete (1988) and Jiang et al. (2006) versus the formulation of Gutman and Innatov (1998). 


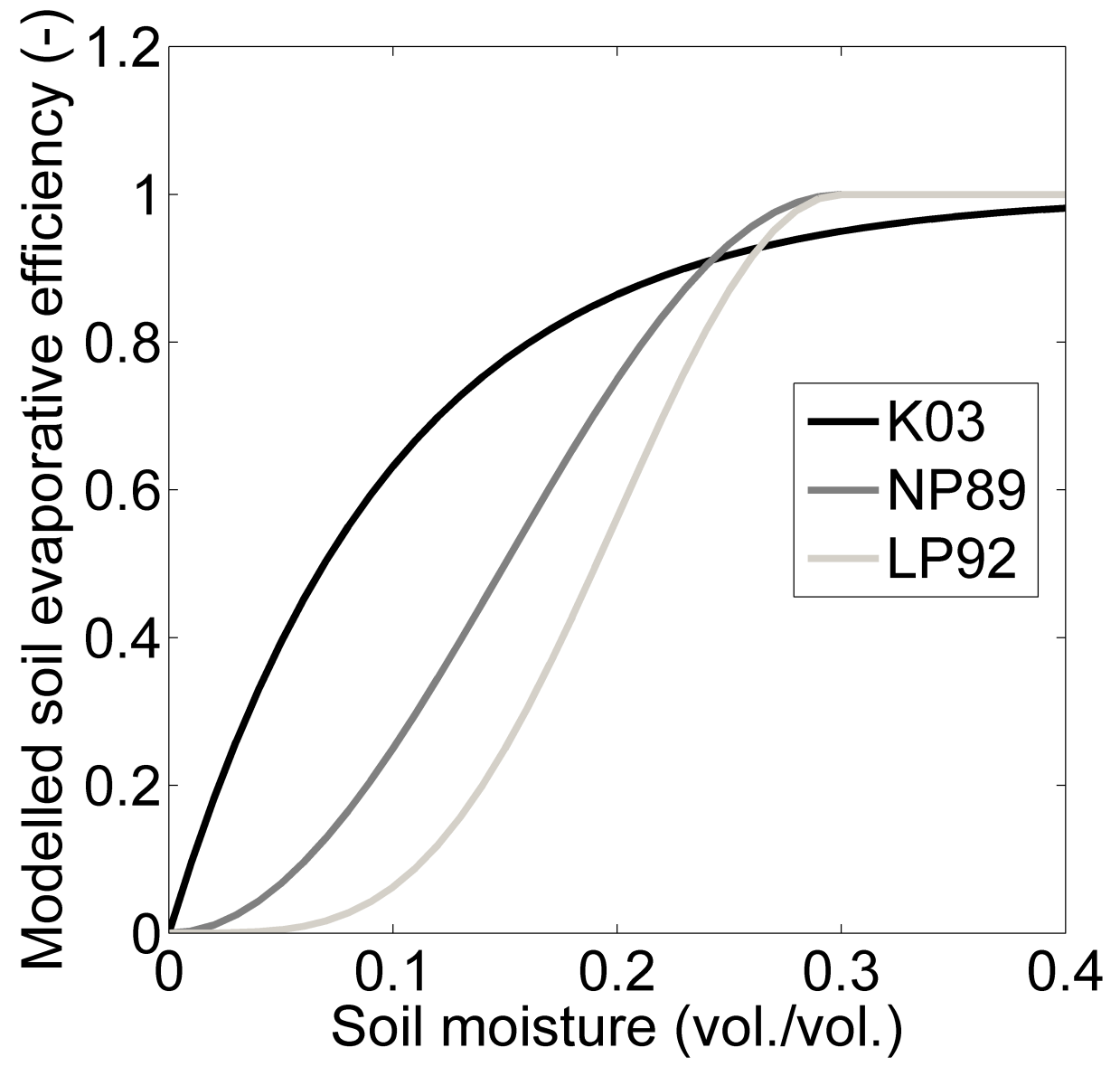

Figure 2: Soil evaporative efficiency $\beta_{\text {mod }}$ simulated using the model from Komatsu (2003), Noilhan and Planton (1989) and Lee and Pielke (1992) for a range of soil moisture values. 

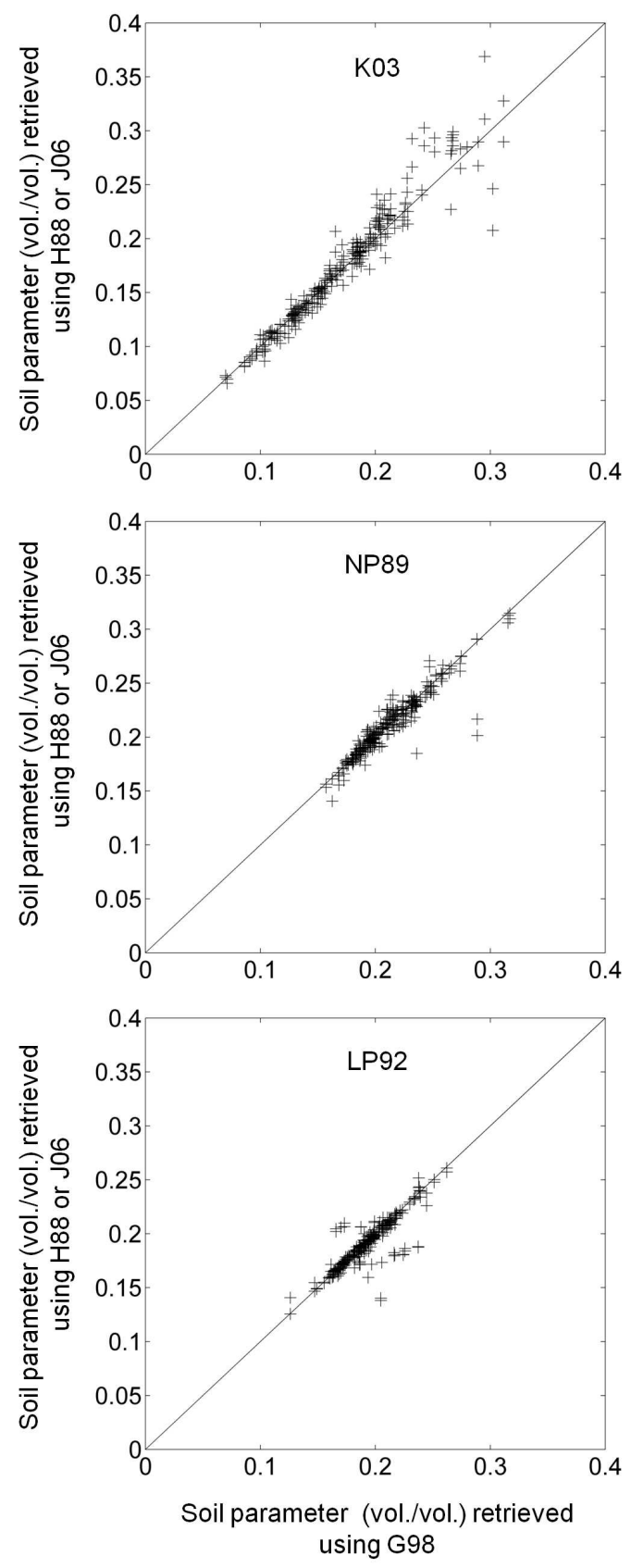

Figure 3: Soil parameter $\theta_{\mathrm{C}}$ retrieved using $f_{\mathrm{H} 88}$ and $f_{\mathrm{J} 06}$ against soil parameter retrieved using $f_{\mathrm{G} 98}$. Scatteplots are presented for the soil evaporative efficiency model K03 (top), NP89 (middle) and LP92 (bottom). 

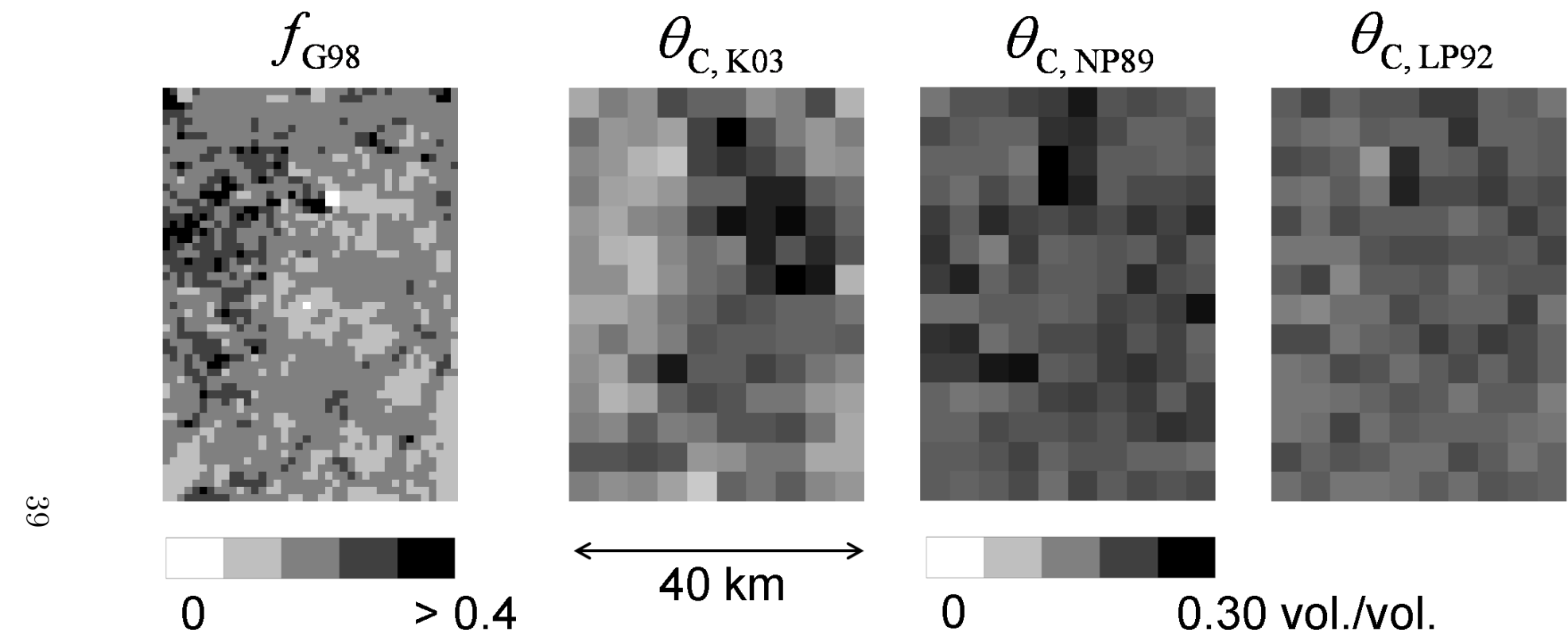

Figure 4: Image of the fractional vegetation cover $f$ derived from G98, and of the soil parameter $\theta_{\mathrm{C}}$ retrieved by inverting models K03, NP89 and LP92. 


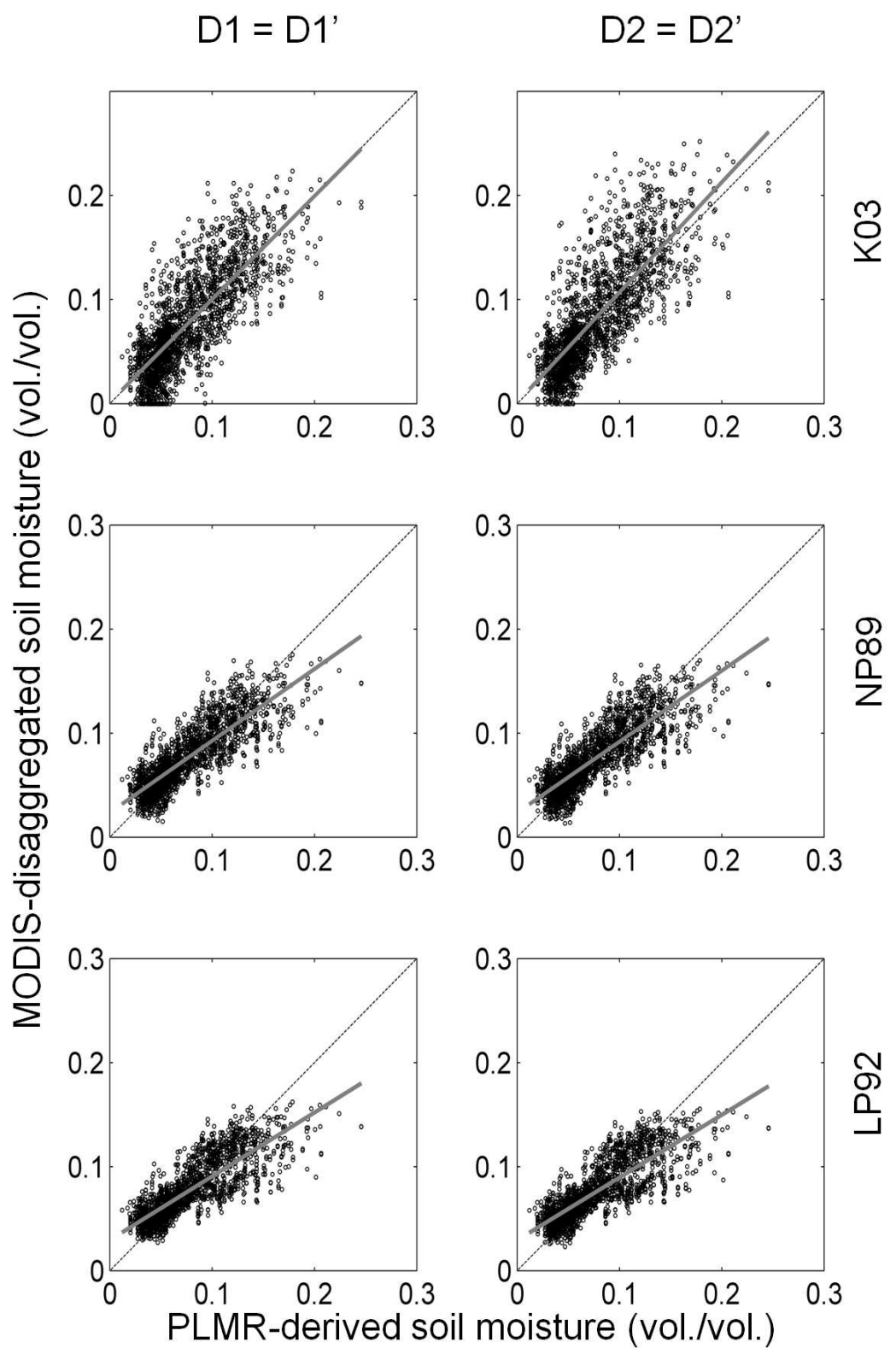

Figure 5: MODIS-disaggregated versus PLMR-derived soil moisture for downscaling relationship D1 (left) and D2 (right) for each of the three soil evaporative efficiency models K03 (top), NP89 (middle) and LP92 (bottom). In the case where soil parameter $\theta_{\mathrm{C}}$ is uniform, D1 is identical to D1' and D2 is identical to D2'. 


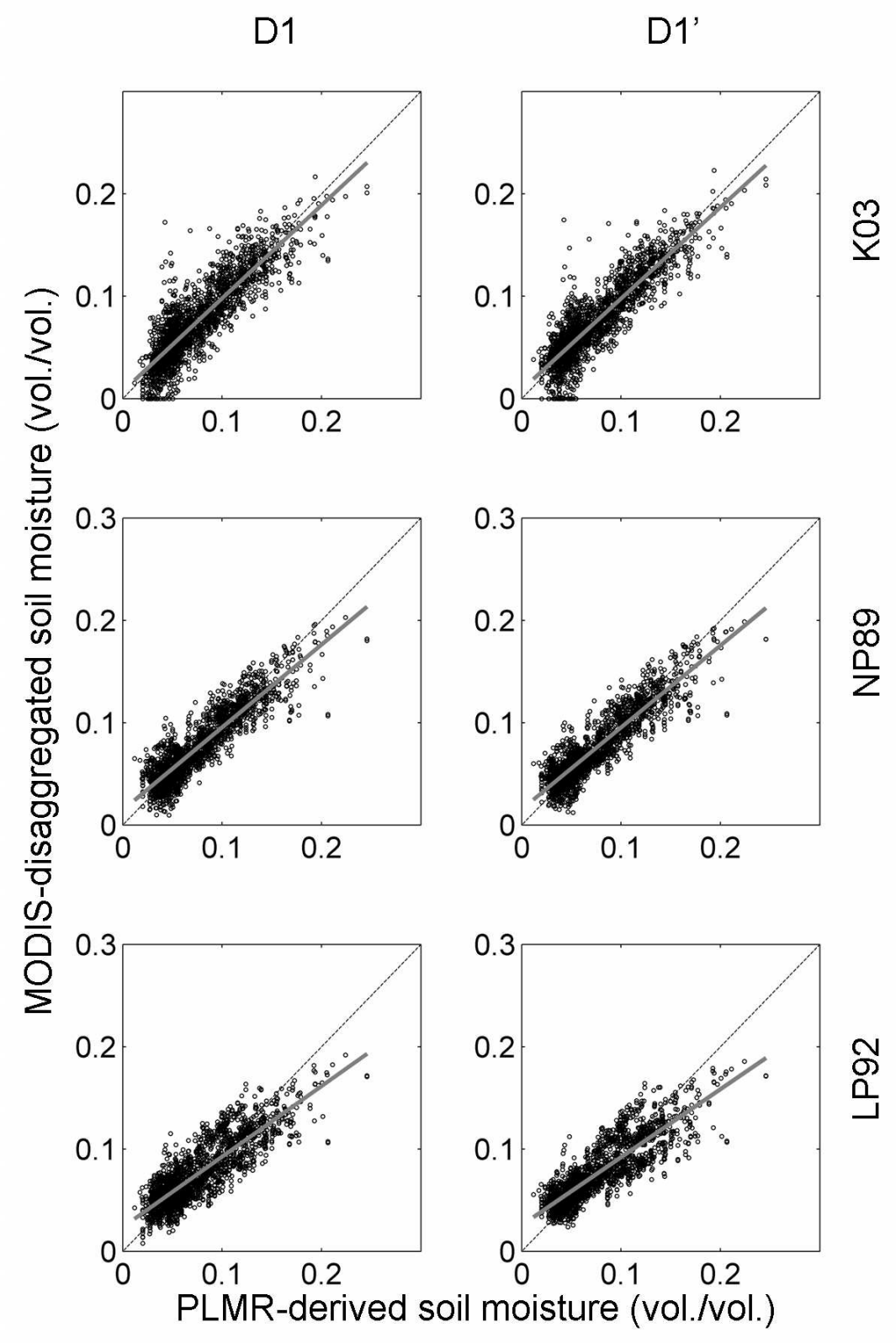

Figure 6: MODIS-disaggregated versus PLMR-derived soil moisture for downscaling relationship D1 (left) and D1' (right) for each of the three soil evaporative efficiency models K03 (top), NP89 (middle) and LP92 (bottom). 


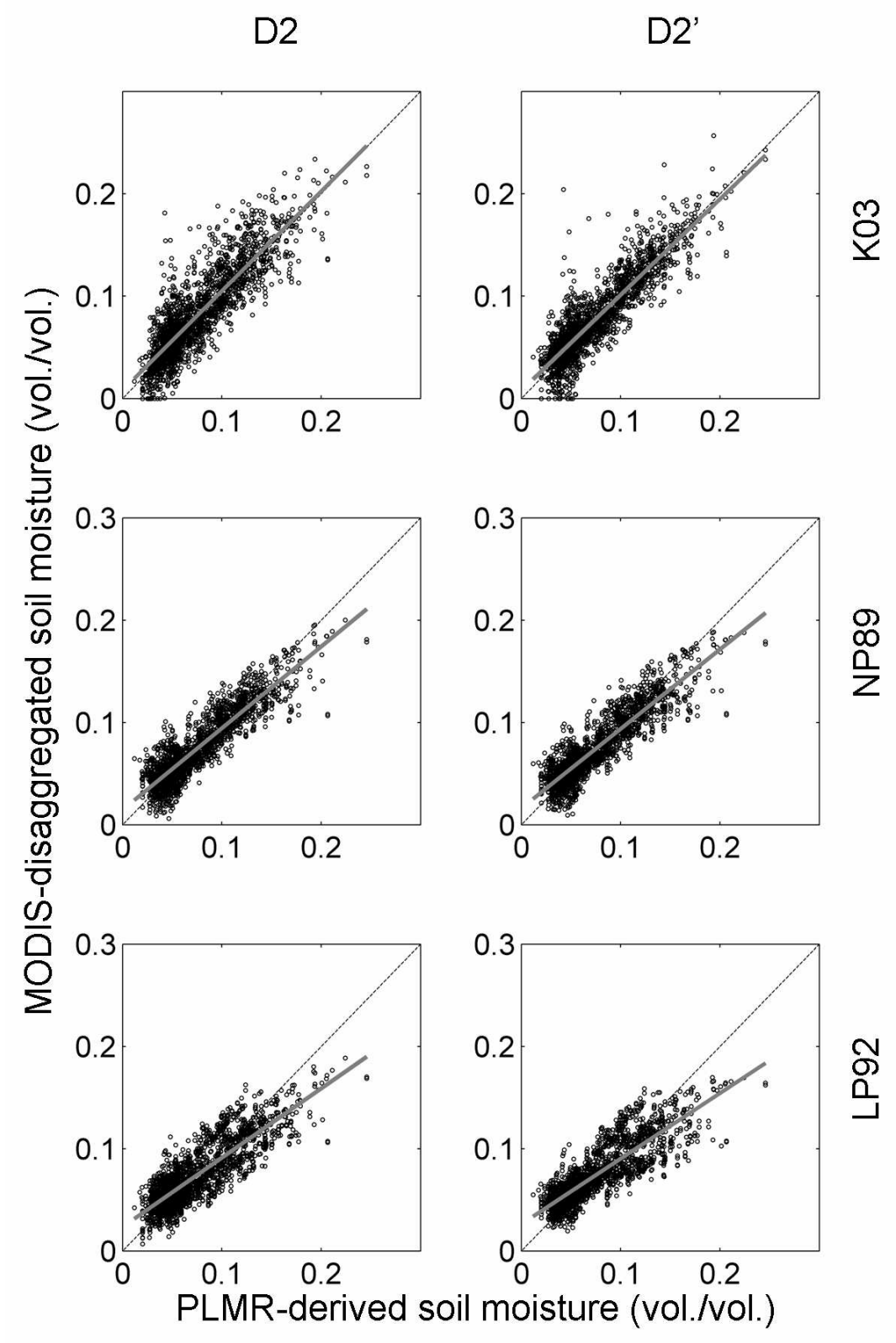

Figure 7: MODIS-disaggregated versus PLMR-derived soil moisture for downscaling relationship D2 (left) and D2' (right) for each of the three soil evaporative efficiency models K03 (top), NP89 (middle) and LP92 (bottom). 


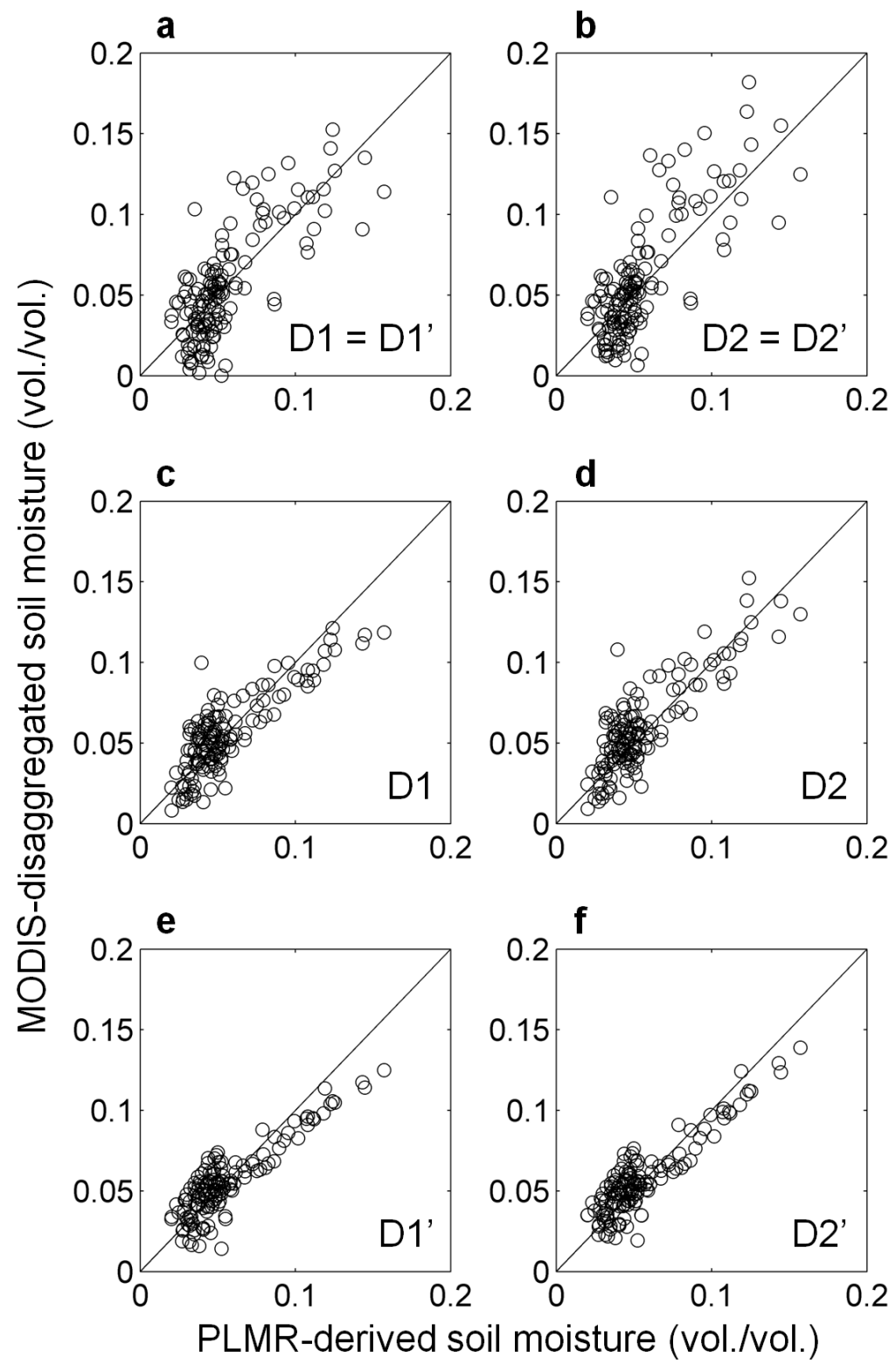

Figure 8: MODIS-disaggregated versus PLMR-derived soil moisture for 9 November Terra and Aqua composited data and downscaling relationship D1=D1' (a), D2=D2' (b), D1 (c), D2 (d), D1' (e) and D2' (f). 


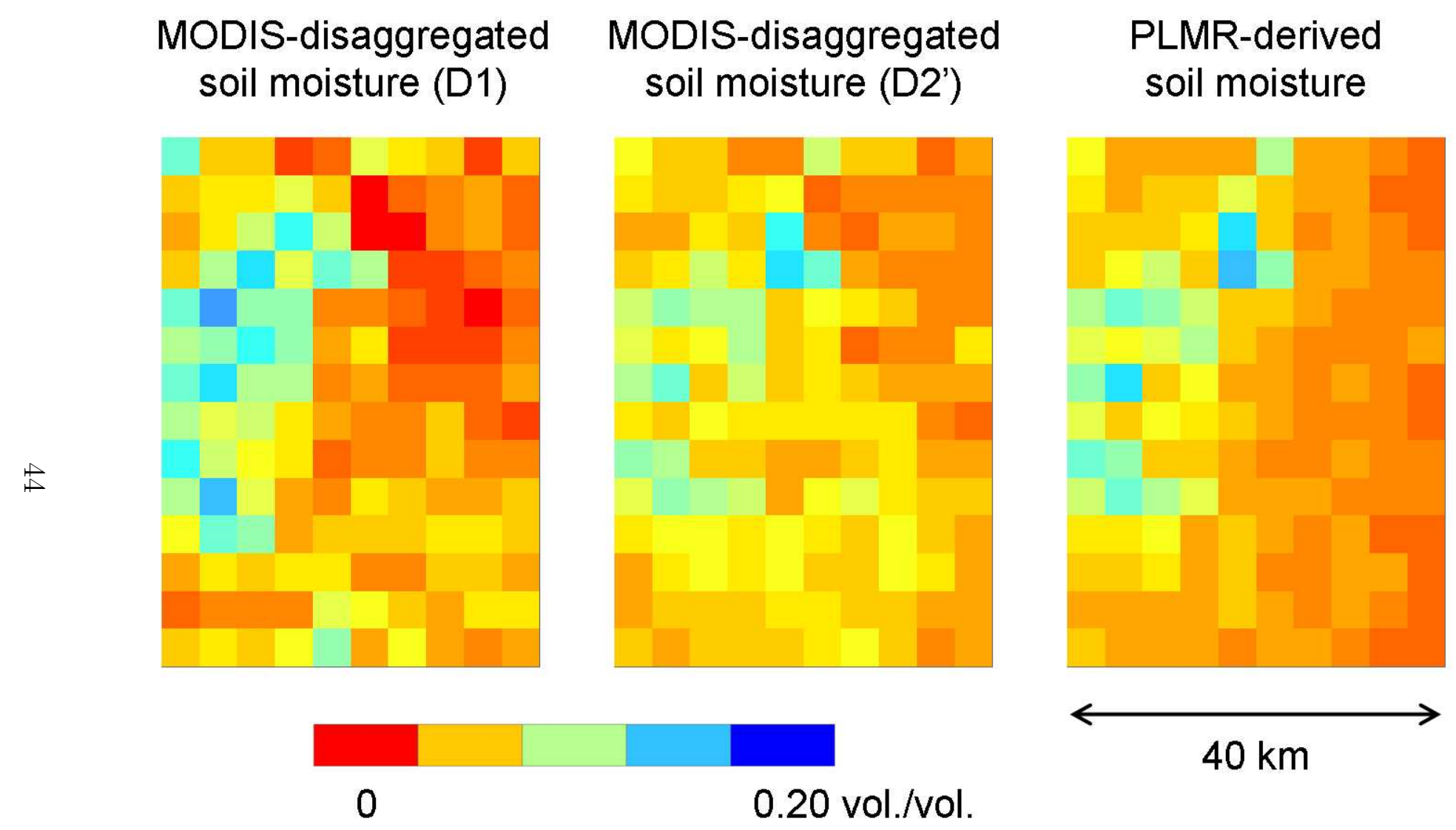

Figure 9: Image of the soil moisture disaggregated using D1=D1' and D2' for 9 November Terra and Aqua composited data, as compared with the image of PLMR-derived soil moisture. 